\title{
INTERPRETAÇÃO DO RISCO DE DESASTRES POR ALUNOS DE ENSINO FUNDAMENTAL E MÉDIO
}

\author{
Luciana de Resende Londe ${ }^{1}$ \\ Erico Soriano ${ }^{2}$ \\ Marcos Pellegrini Coutinho ${ }^{3}$ \\ Víctor Marchezini ${ }^{4}$
}

\begin{abstract}
Resumo: Este trabalho traz como motivação a compreensão do imaginário infantil $e$ adolescente entre um público que, em sua maioria, não vivenciou um desastre, apesar de morar em áreas de risco. A investigação revela o perfil de um grupo importante, caracterizando-se como um significativo ponto de partida para trabalhos de educação $e$ prevenção de desastres, uma vez que oferece como base a análise de crenças e expectativas relacionadas aos desastres. Para caracterizar este perfil, foram aplicados questionários semiestruturados a alunos de ensino fundamental e médio de escolas públicas localizadas próximas a áreas de risco em Campos do Jordão (SP). Apesar da presença de várias áreas de risco no município, a maioria dos entrevistados não reconhece este risco como parte de sua realidade. É importante que o órgão de Defesa Civil (DC), juntamente com as comunidades envolvidas, elabore um planejamento especial de ações de evacuação para este grupo vulnerável na iminência de um desastre e também medidas diferenciadas de atendimento pós-impacto. Os entrevistados mostraram-se receptivos a possíveis ações da $D C$ e a discussões gerais sobre o tema desastres. Recomendamos uma parceria entre as escolas e a DC local para atividades de educação e planejamento.
\end{abstract}

Palavras-chave: movimentos de massa; defesa civil; vulnerabilidade sócio-ambiental; prevenção de desastres.

\section{Understanding of disasters risks by brazilian students}

\begin{abstract}
We aimed to evaluate children and teenagers' understanding about disasters, from a group of people that has not experienced a disaster. This evaluation is expected to serve as a reference for disaster prevention, because it provides beliefs and expectations about disasters, from a public who live in or near risk areas. Students with ages from 10 to 21 years were invited to answer a survey to characterize their beliefs about disaster and disaster prevention. Even though there are many risk areas in their municipality (Campos do Jordão, $S P)$, most of the students do not recognize the risk of natural disasters as part of their reality.
\end{abstract}

\footnotetext{
${ }^{1}$ Doutorado em Sensoriamento Remoto pelo Instituto Nacional de Pesquisas Espaciais - INPE. Mestrado em Engenharia Agrícola pela Universidade Estadual de Campinas - UNICAMP. Graduação (Bacharelado e Licenciatura Plena) em Ciências Biológicas pela Universidade Federal de Uberlândia - UFU. É Gerente de Pesquisas em Desastres Naturais no CEMADEN - Centro Nacional de Monitoramento e Alertas de Desastres Naturais. E-mail: luciana.r.londe@gmail.com

${ }^{2}$ Graduação em Geografia (licenciatura e bacharelado) pela Universidade Estadual Paulista Júlio de Mesquita Filho-UNESP. Mestrado em Geografia pela Universidade Estadual Paulista Júlio de Mesquita Filho-UNESP. Doutorado em Ciências da Engenharia Ambiental pela Escola de Engenharia de São Carlos da Universidade de São Paulo EESC-USP. Analista de Pesquisa em Desastres Naturais no Centro Nacional de Monitoramento e Alertas de Desastres Naturais (CEMADEN). E-mail: ericogeo@gmail.com

${ }^{3}$ Possui graduação em Engenharia Florestal pela Universidade Federal de Viçosa. Mestrado em Produção Vegetal pela Universidade Estadual do Norte Fluminense Darcy Ribeiro. Pesquisador do Centro Nacional de Monitoramento e Alerta de Desastres NaturaisCEMADEN. E-mail: marcos.coutinho@cemaden.gov.br

${ }^{4}$ Bacharel em Ciências Sociais pela Universidade Federal de São Carlos e Licenciado em Ciências Sociais pela Universidade Estadual Paulista - UNESP/FCL- Araraquara. Especialista em Formação Docente para o Ensino Superior pela Anhanguera-Uniderp. Mestre em Sociologia pela Universidade Federal de São Carlos. Especialista em Direitos Humanos, Gestão Global de Riscos e Políticas Públicas de Prevenção de Desastres pela Fundação Henry Dunant - América Latina. Doutor em Sociologia pelo PPGS/UFSCar. Analista operacional em desastres no Centro Nacional de Monitoramento e Alerta de Desastres Naturais (CEMADEN). E-mail: victor.marchezini@cemaden.gov.br
} 
Considering that the interviewees were receptive to meetings and discussions with the municipality's institution of civil defense, we recommend that they make together an evacuation planning for the imminence of a disaster, based on the community's needs and limitations. It is also advisable that the civil defense plan special measures for post-disaster care. We also recommend a partnership among community, civil defense and local schools to create awareness and preparedness activities.

Keywords: landslides; civil defense; societal-environmental vulnerability; disasters prevention.

\section{INTRODUÇÃO}

Os desastres associados a enchentes, movimentos de massa e estiagens, provocam danos diversos às populações diretamente vulneráveis a estes processos, além de consequências ambientais, socioeconômicas e sanitárias negativas.

Entre os desastres que ocorrem no Brasil, os deslizamentos de encostas são responsáveis pelo maior número de óbitos fatais (CERRI, 1993; AUGUSTO FILHO, 1994, TOMINAGA, 2009). Os deslizamentos ou escorregamentos são movimentos coletivos de massa e/ou material sólido, como solo, rochas e vegetação, ao longo de uma encosta, sob influência direta da gravidade (SELBY, 1993). Os movimentos de massa fazem parte da evolução geomorfológica em regiões serranas, processo natural de formação da paisagem. Entretanto, a ocupação de áreas desfavoráveis, sem um planejamento adequado do uso do solo e sem técnicas adequadas de estabilização, aumenta a possibilidade da ocorrência de acidentes associados a estes processos, que muitas vezes atingem dimensões de desastres (TOMINAGA, 2007).

O Município de Campos do Jordão, de acordo com dados do Instituto de Pesquisa Tecnológica (IPT, 2000), possui áreas de riscos de escorregamento classificados como alto ou muito alto. Destaca-se que sua população em 2010 era de 47.789 habitantes, dos quais 47.491 (99,37\%) residiam em área urbana (FIBGE, 2010). O quadro natural da região, associado a aspectos geológicos, geomorfológicos e climáticos, em conjunção com a forma e a intensidade das intervenções antrópicas sobre os morros, condicionam situações favoráveis à ocorrência de grandes movimentos de massa, a exemplo do ocorrido em agosto de 1972 que culminou em dez mortes. Em anos posteriores novos deslizamentos ocorreram e contribuíram para a concretização de novos desastres: em janeiro de 1991, um relatório interno da Comissão Municipal de Defesa Civil apontou um total de 149 "desabamentos de barracos", com quatro vítimas; nos primeiros dias do ano 2000, novos deslizamentos vitimaram dez pessoas, deixaram mais de 103 feridos em hospitais e revelaram 347 
moradias em risco emergencial e 423 em risco iminente. Em relatório técnico produzido pelo Instituto de Pesquisas Tecnológicas no ano 2000 (IPT, 2000), estimou-se que 1.500 moradias e 7.000 pessoas estivessem expostas a deslizamentos, ou seja, 15,82\% de uma população total de 44.252 pessoas (FIBGE, 2000).

Apesar do risco de desastres relacionado às características naturais e de ocupação urbana do município, é possível aumentar a resiliência e a capacidade de resposta desta comunidade. Em atividades de prevenção, é importante incluir crianças e adolescentes, pois esta parcela da população encontra-se no momento mais adequado para aprender e refletir sobre os temas que lhe são propostos, além de multiplicar este conteúdo entre seus familiares. Considerando que as crianças e adolescentes são atores fundamentais no processo de percepção quanto ao risco, nosso objetivo foi analisar as visões deste público com relação a suas moradias, aos riscos a que estão expostos, à interação com a Defesa Civil local e às expectativas quanto a ações futuras. Buscamos também pautar estas análises em um direcionamento para possíveis abordagens educativas.

\section{Fundamentação teórica e contextualização}

Veyret (2007, p. 11) apresenta o termo risco sob a seguinte interpretação:

O risco, objeto social, define-se como a percepção do perigo, da catástrofe possível. Ele existe apenas em relação a um indivíduo e a um grupo social ou profissional, uma comunidade, uma sociedade que o apreende por meio de representações mentais e com ele convive por meio de práticas específicas. Não há risco sem uma população ou indivíduo que o perceba e que poderia sofrer seus efeitos. Correm-se riscos, que são assumidos, recusados, estimados, avaliados, calculados. O risco é a tradução de uma ameaça, de um perigo para aquele que está sujeito a ele e o percebe como tal.

Os desastres que provocaram mais impactos no município de Campos do Jordão (movimentos de massa nos anos de 1972 e 2000) ocorreram quando alguns alunos entrevistados neste trabalho ainda não tinham nascido ou tinham pouca idade ${ }^{5}$. Como existe a probabilidade de novos desastres de mesma tipologia no município, estas pessoas precisam preparar-se, porém não podem tomar como base sua experiência e sim a experiência das gerações anteriores. Nas palavras de Beck, Giddens e Lash (1997):

Hoje em dia, a noção de "risco" é fundamental para a cultura moderna justamente porque grande parte do nosso pensamento tem de ser do tipo

${ }^{5}$ Os questionários foram aplicados em 26/03/2013 
"como se". Em muitos aspectos de nossas vidas, tanto individual quando coletiva, temos de construir regularmente futuros potenciais, sabendo que essa mesma construção pode, na verdade, impedir que eles venham a acontecer. Novas áreas de imprevisibilidade são muito frequentemente criadas pelas próprias tentativas que buscam controlá-las.

Este fato torna peculiar a representação do risco por este público específico, pois há um conflito de abordagens, englobando a experiência dos pais ou de outros adultos que presenciaram o desastre e o relatam às novas gerações, a informação que chega pelos meios de comunicação e a experiência dos atores em questão, que não vivenciaram o desastre, mas moram em áreas de risco.

Faria (2002) relata que todos os indivíduos confrontam-se desde o nascimento com duas necessidades de satisfação contraditórias: a busca da segurança e a busca de estímulos, que se expressa pela exploração do seu ambiente e constitui uma fonte de riscos. Ainda de acordo com Faria (2002), "o risco é um dos conceitos mais complexos que a criança precisa compreender e manipular durante seu desenvolvimento", pois esta construção da noção de perigo é derivada da busca da ordem e da lei e somente quando estes conceitos já estão construídos de forma satisfatória a criança pode integrá-los. Baseado nas faixas etárias estudadas por Piaget (1967), Faria (2002) descreve um modelo de construção do perigo com três fases: na primeira (0 a 7 anos), a noção de risco ainda não pode ser compreendida pela criança; na segunda (de 7 a 11 anos), a criança compreende progressivamente a noção de perigo e de risco, mas ainda não consegue integrar a noção de probabilidade e na terceira fase (de 11 a 15 anos), ela toma decisões raciocinando com a noção de probabilidade. Entretanto, Faria (2002) ressalta que a percepção do perigo físico e da perda da vida depende mais das características da situação do que da idade.

Para sobreviver, os animais devem ser sensíveis aos sinais de perigo; eles precisam conhecer o medo. Individual e coletivamente, os seres humanos não são exceção (TUAN, 2005, p. 57).

Oliveira e Nunes (2007, p.81) ressaltam, além das características da situação, as características individuais de cada pessoa na percepção do risco:

As pessoas percebem de acordo com sua ótica individual, isto é, em consonância com sua personalidade, refletindo sua natureza, anseios, experiências e desejos. Além disso, a percepção é distinta de acordo com o gênero, classe social, idade, profissão, escolaridade, local de moradia e ambiente cultural sendo, portanto, altamente exploratória e seletiva. 
A percepção do risco por crianças e adolescentes, portanto, revela o perfil de um público importante, caracterizando-se como um significativo ponto de partida para trabalhos de educação e prevenção de desastres. Pavan (2009) afirma que, na redução da vulnerabilidade, as crianças e os jovens tem um papel importante para a resolução dos problemas, uma vez que a preparação antecipada pode fazer com que elas sejam capazes de se proteger e alertar a própria família para minimizar ou evitar os danos.

A Lei 12.608/12, que Institui a Política Nacional de Proteção e Defesa Civil (PNPDEC) apóia e sugere atividades de educação para desastres para crianças e adolescentes através da alteração do artigo 26 da Lei de diretrizes e bases da educação nacional de 20/12/1996, o qual passa a vigorar acrescido do parágrafo 70 que determina que "os currículos do ensino fundamental e médio devem incluir os princípios da proteção e defesa civil e a educação ambiental de forma integrada aos conteúdos obrigatórios".

Os conteúdos curriculares das escolas de todo o país tem como referência os Parâmetros Curriculares Nacionais (PCNs), que são as diretrizes elaboradas pelo Ministério da Educação e representam a base conceitual do que deve ser ensinado nas escolas, buscando uma homogeneização dos conteúdos no território nacional, sobrepondo as competências dos Estados e Municípios (DIRETRIZES, 2008, e BRASIL 1997). Pedagogicamente, os PCNs permitem ações e trabalhos que contemplam questões locais e de interesse social diferenciado, possibilitando uma ampliação de conteúdos, debates e questionamentos, principalmente através de seus temas transversais ${ }^{6}$.

De acordo com a Secretaria Estadual de Educação do Estado de São Paulo, os conteúdos transversais, ministrados nos ensinos médio e fundamental, podem contribuir para uma formação mais humana, em função da multiculturalidade.

Esse fato se dá quando o docente apropria-se da realidade, do cotidiano e da leitura de mundo do discente, e os conecta aos temas da atualidade, estes, presentes nos temas transversais. Atenta-se que, estes são os eixos geradores de saberes, a partir das experiências dos alunos, assim como os eixos de conexão entre os conteúdos tradicionais (SÃO PAULO, 2012, p.3).

A inserção do tópico "Noções Gerais de Defesa Civil e Percepção de Riscos" nas unidades de ensino, como um tema transversal dos Parâmetros Curriculares Nacionais, representa a possibilidade de uma universalização do assunto e o potencial de atingir a totalidade dos

6 Os temas transversais expressam conceitos e valores básicos à democracia e à cidadania e obedecem a questões importantes e urgentes para a sociedade contemporânea. A ética, o meio ambiente, a saúde, o trabalho e o consumo, a orientação sexual e a pluralidade cultural não são disciplinas autônomas, mas temas que permeiam todas as áreas do conhecimento, e estão sendo intensamente vividos pela sociedade, pelas comunidades, pelas famílias, pelos alunos e educadores em seu cotidiano. (PCNs) 
alunos de ensino fundamental e médio do país. Desta forma, o desenvolvimento e a transmissão deste conteúdo podem contribuir positivamente para a identificação de áreas de risco e de populações em condição de vulnerabilidade e para o principio da construção de uma cultura de risco, pautada na informação e no diálogo, buscando a redução de vítimas nos desastres. Neste sentido, de acordo com Valencio et. al. (2007, p.15-16), há a necessidade de informar a criança sobre o tema dos riscos para prepará-la, em todos os sentidos, para esta realidade cada vez mais comum nos centros urbanos.

Os educadores atuantes devem levar em consideração não só esta tríade de vulnerabilidades, mas recorrer a uma interação que a coloque em contato com essa realidade de uma maneira positiva: onde couber, antecipatória, sem o risco de incitar ansiedades desnecessárias; de outro modo, num pós-evento em que a reelaboração do fenômeno alivie o sofrimento vivenciado. Tal interação pode se dar utilizando uma ferramenta de linguagem em que a criança possa expressar o seu entendimento do mundo bem como suas limitações de entendimento; possa expressar os seus sentimentos e que isso também traduza uma dimensão física do mundo, ou seja, uma abstração, na qual ela também possa se projetar fisicamente. A criança precisa, por fim, de concretude, isto é, condições materiais para expressar seu mundo interior e sua relação com o mundo externo.

Destaca-se que os estudantes, assim como os demais membros das respectivas comunidades, têm a noção de que se encontram em determinado risco, mesmo que, no caso das crianças, não compreendam toda a dinâmica dos processos e consequências desse risco. A importância de trabalhos deste tipo se dá no estreitamento do contato com os órgãos de Defesa Civil, e na difusão de medidas preventivas, que podem reduzir a vulnerabilidade a riscos locais. Neste sentido, para Valencio et. al. (2005) e Valencio (2007), o diálogo entre os chamados leigos e os peritos é de fundamental importância para que sejam desenvolvidas medidas mitigadoras mais eficazes, com base na percepção dos riscos dos grupos sociais e pela importância da experiência local destas populações, ressaltando-se a legitimidade e a importância da elaboração de propostas e soluções em conjunto.

Os PCNs possuem uma vocação de flexibilidade, considerando elementos de diversidade cultural e as diferentes dimensões da prática educacional. A inserção da temática de Defesa Civil e prevenção de desastres nas escolas abre a possibilidade da construção de um comportamento comunitário e solidário, visando à preocupação coletiva com a segurança de toda a comunidade (LIMA, 2006). 
As pesquisas envolvendo a percepção do risco de crianças e adolescentes geralmente abordam situações pós-impacto (PAVAN, 2009), em que as crianças são convidadas a fazer um desenho e/ou relatar a experiência vivida, sendo percebidas apenas como vítimas dos desastres em vez de agentes ativos de mudanças e capazes de transformar a sociedade. Este trabalho traz como motivação a compreensão do imaginário infantil e adolescente entre um público que, em sua maioria, não vivenciou um desastre, apesar de morar em áreas de risco. Esta investigação fornece um vasto material para atividades de prevenção, uma vez que oferece como base e ponto de partida a análise de crenças e expectativas relacionadas aos desastres.

\section{MÉTODO}

\section{Local de estudo}

O local escolhido para estudo foi o município de Campos do Jordão (SP), por ter um histórico de desastres, principalmente envolvendo movimentos de massa, e, também, uma elevada concentração de pessoas que ainda residem em áreas de risco, em situação de vulnerabilidade. Entre as áreas consideradas de risco por parte do poder público municipal e pela bibliografia, destaca-se o Morro do Britador ${ }^{7}$, onde moram vários estudantes que participaram da pesquisa. Este local compreende uma extensa porção de encosta de morro, cuja vertente, ocupada predominantemente por população de baixa renda, está voltada para o Córrego do Capivari na porção central da cidade (ROSA-FILHO; CORTEZ, 2010). A ocupação desordenada do sopé ao alto da encosta, em patamares de corte e aterro, tornou a área extremamente vulnerável à ocorrência de acidentes de escorregamentos (IPT, 2003; MODENESI-GAUTTIERI; HIRUMA, 2004; ROSA-FILHO; CORTEZ, 2010).

No Morro do Britador, as situações de risco de acidentes de escorregamentos podem ser subdivididas em quatro categorias (IPT, 2003; ROSA-FILHO; CORTEZ, 2010):

$\checkmark$ acidentes relacionados a rupturas pontuais em taludes de corte e aterro;

$\checkmark$ acidentes associados à ocorrência sucessiva de escorregamentos planares rasos de dimensões médias a grandes, mobilizando os depósitos de material lançado e as coberturas de solo superficial;

\footnotetext{
${ }^{7}$ O morro do Britador representa uma área de alta declividade, próximo ao Bairro Santo Antônio, cuja estrutura foi modificada em função das atividades de explotação de uma mineradora que retirava brita do local.
} 
$\checkmark$ acidentes relacionados a movimentos de massa deflagrados pela convergência das águas pluviais em direção ao eixo central de drenagem no fundo do vale;

$\checkmark$ acidentes decorrentes de escorregamentos planares de porte médio a grande, em porções de ruptura de declive associadas a taludes de corte de alturas excessivas, em trechos da porção média e inferior das encostas.

Também destaca-se como área de risco a Vila Santo Antônio, que apresenta um grande número de moradias de padrão construtivo bastante heterogêneo, ocupando terrenos de uma sub-bacia de drenagem bem definida, que apresenta vertentes com amplitudes topográficas da ordem de $100 \mathrm{~m}$ e diversos trechos com declividades naturais elevadas (ROSA-FILHO; CORTEZ, 2010).

Além da Vila Santo Antônio e do Bairro do Britador, são considerados áreas de intervenção pela Prefeitura Municipal de Campos do Jordão os seguintes locais: Vila Albertina, Acampamento dos Pumas, Morro das Andorinhas, Atalaia/Senac, Brancas Nuvens, Beira Rio, Biquinha, Cachoeirinha, Campista, Vila Carapina, Ferradura, Fracalanza, Gavião Gonzaga, Gruta dos Crioulos, Jardim Guararema, Matadouro, Vila Paulista Popular, Leonor Mendes de Barros, Recanto Feliz, Rua Cambará - Subida da Minalba, Vila Siomara, Taquaral, Vila Maria e Vale Encantado.

\section{Questionários e público abordado}

Foram aplicados 519 questionários a alunos do Ensino Fundamental e Médio, em três escolas públicas com localização próxima a áreas de risco: Escola Municipal Anísio Teixeira, Escola Municipal Laurinda da Mata e "Escola Estadual Vila Albertina" ${ }^{8}$. Grande parte dos alunos destas escolas mora em áreas de risco e alguns tiveram que sair de suas residências e vivem atualmente no CDHU - Companhia de Desenvolvimento Habitacional e Urbano. Uma destas escolas, a E.M. Anísio Teixeira, foi interditada anteriormente pela Defesa Civil, sendo reaberta em 8 de fevereiro de 2011.

Foram utilizados questionários semi-estrututrados, com questões abertas e fechadas (MINAYO 2004), permitindo que os alunos tivessem a possibilidade de discorrer sobre as questões propostas. Os questionários foram aplicados em 26/03/2013. Foram feitas visitas às diferentes séries de ensino médio e fundamental das referidas escolas, com uma

${ }^{8}$ no período de realização do trabalho esta escola no bairro Vila Albertina ainda não dispunha de nome oficial, sendo aqui denominada de Escola Estadual Vila Albertina. 
explicação breve sobre o tema a ser desenvolvido e orientações sobre o preenchimento dos questionários.

O primeiro conjunto de perguntas englobou informações de caracterização das pessoas que participaram da análise. Dando sequência às questões que compõem o perfil básico dos entrevistados, o segundo bloco de perguntas teve a finalidade de caracterizar o modo como os entrevistados entendem e se relacionam com o local onde moram, o modo como entendem as informações que recebem e a avaliação que fazem sobre sua segurança e a segurança de suas famílias.

O último bloco de perguntas foi direcionado à relação dos entrevistados com a Defesa Civil local, explorando, inicialmente, se estas pessoas têm conhecimento da existência da Defesa Civil em sua cidade e se saberiam entrar em contato. Em seguida exploramos se já houve um contato mais próximo (se a Defesa Civil já esteve no bairro do entrevistado) e como seria a receptividade desta pessoa e das pessoas que moram com ela a possíveis intervenções da Defesa Civil em seu bairro, considerando a necessidade de sair da residência. Procuramos identificar planejamentos por parte do entrevistado caso ocorra algum desastre (se sairiam de casa, se saberiam para onde ir, se ligariam para a Defesa Civil). Por fim, verificamos se o tema desastres já havia sido trabalhado anteriormente na escola e se alunos estariam receptivos para discutir este conteúdo com a DC ou com outros profissionais.

\section{RESULTADOS E DISCUSSÃO}

\section{Perfil dos alunos entrevistados}

Foram entrevistados alunos do sexto ano do ensino fundamental ao terceiro ano do ensino médio (Tabela 1).

Dos alunos entrevistados, 455 (87,5\%) nasceram em Campos do Jordão. Entre os demais, 36 são provenientes de outras cidades do estado de São Paulo, 25 têm origem em outros estados e uma pessoa nasceu no Japão. A maioria mora em Campos do Jordão há mais de 10 anos e vive na mesma residência há 10 anos ou menos.

Em relação ao local de residência, 217 alunos $(46,7 \%$ do total)moram em bairros considerados áreas de risco pela defesa civil: Vila Albertina (88), Vila Santo Antônio (62), Britador (20), Brancas Nuvens (35) e Vila Paulista Popular (12) (Figura 1). A maioria mora com mais 4 pessoas e em 4,86\% das residências há um morador com necessidades especiais, englobando deficiências auditiva, visual, mental e de locomoção. 


\begin{tabular}{|c|c|c|c|c|c|c|c|}
\hline & & $\begin{array}{c}\text { E.M. Anísio } \\
\text { Teixeira } \\
\end{array}$ & $\begin{array}{c}\text { E.M. Laurinda } \\
\text { da Mata }\end{array}$ & $\begin{array}{c}\text { E.E. Vila } \\
\text { Albertina }\end{array}$ & Total parcial & Total parcial (\%) & Total Geral (\%) \\
\hline \multirow[b]{3}{*}{60 ano - EF } & feminino & 19 & 13 & & 32 & 45,71 & \multirow[b]{3}{*}{13,46} \\
\hline & masculino & 25 & 13 & & 38 & 54,29 & \\
\hline & Total & 44 & 26 & & 70 & 100 & \\
\hline \multirow[b]{3}{*}{ 7o ano - EF } & feminino & 27 & 16 & & 43 & 50,00 & \multirow[b]{3}{*}{16,54} \\
\hline & masculino & 28 & 15 & & 43 & 50,00 & \\
\hline & Total & 55 & 31 & & 86 & 100 & \\
\hline \multirow[b]{3}{*}{80 ano - EF } & feminino & & 37 & & 37 & 58,73 & \multirow[b]{3}{*}{12,12} \\
\hline & masculino & & 26 & & 26 & 41,27 & \\
\hline & Total & & 63 & & 63 & 100 & \\
\hline \multirow[b]{3}{*}{90 ano - EF } & feminino & 16 & & & 16 & 61,54 & \multirow[b]{3}{*}{5,00} \\
\hline & masculino & 10 & & & 10 & 38,46 & \\
\hline & Total & 26 & & & 26 & 100 & \\
\hline \multirow[b]{3}{*}{10 ano - EM } & feminino & & & 84 & 84 & 54,55 & \multirow[b]{3}{*}{29,62} \\
\hline & masculino & & & 70 & 70 & 45,45 & \\
\hline & Total & & & 154 & 154 & 100 & \\
\hline \multirow[b]{3}{*}{20 ano-EM } & feminino & & & 46 & 46 & 46,00 & \multirow[b]{3}{*}{19,23} \\
\hline & masculino & & & 54 & 54 & 54,00 & \\
\hline & Total & & & 100 & 100 & 100 & \\
\hline \multirow[b]{3}{*}{30 ano - EM } & feminino & & & 14 & 14 & 66,67 & \multirow[b]{3}{*}{4,04} \\
\hline & masculino & & & 7 & 7 & 33,33 & \\
\hline & Total & & & 21 & 21 & 100 & \\
\hline \multicolumn{2}{|c|}{ Total geral } & 125 & 120 & 275 & 520 & & \multirow[b]{2}{*}{100} \\
\hline \multicolumn{2}{|c|}{ Total geral (\%) } & 24,04 & 23,08 & 52,88 & & & \\
\hline
\end{tabular}

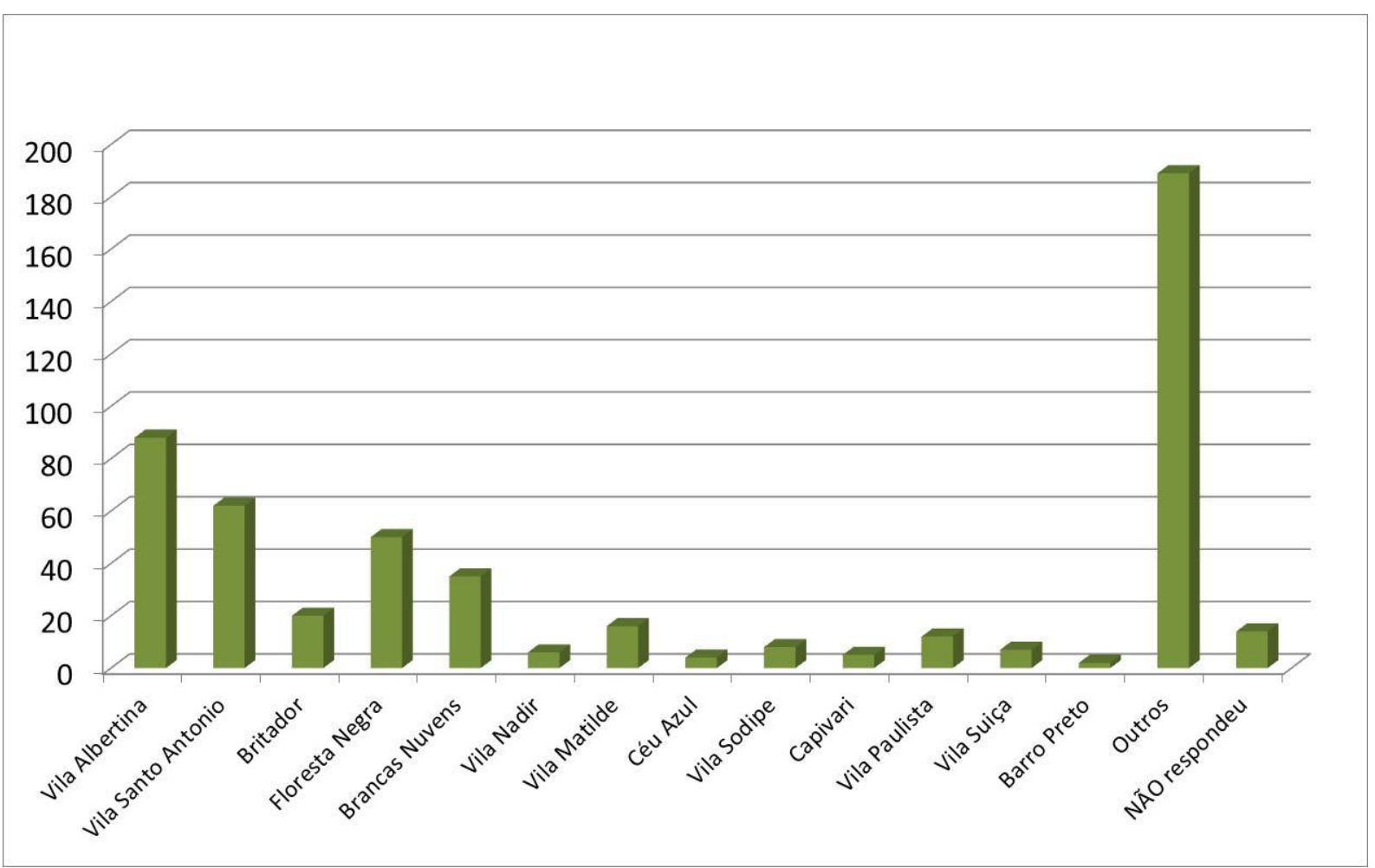

Figura 1: Locais de residência dos entrevistados. Nota: Barro Preto e Vila Santo Antônio correspondem à mesma localização, porém optamos por manter os nomes originais mencionados nas respostas. 


\begin{abstract}
A faixa etária dos entrevistados é de 10 a 21 anos, sendo que a maioria dos entrevistados tem 15 anos de idade.
\end{abstract}

\title{
Percepção de risco
}

De acordo com Veyret (2007):

O risco é uma construção social. A percepção que os atores têm de algo que representa um perigo para eles próprios, para os outros e seus bens, contribui para construir o risco que não depende unicamente de fatos ou processos objetivos (p. 23).

Também de acordo com Veyret (2007):

O risco e a percepção que se tem dele não podem ser enfocados sem que se considere o contexto histórico que os produziu e, especialmente, as relações com o espaço geográfico, os modos de ocupação do território e as relações sociais características da época. (p. 26)

O primeiro passo para perceber a complexidade dos riscos associados ao local onde se mora é o conhecimento dos fatores que podem desencadear um desastre ou aumentar a sua vulnerabilidade. A pergunta "Você consegue saber quando vai chover?" foi elaborada com a finalidade de analisar a habilidade dos entrevistados para prever ou obter previsão de chuvas, que são um fator desencadeador dos movimentos de massa, comuns nos locais onde moram. Vários alunos mencionaram a previsão do tempo obtida através da mídia (televisão, internet, celular), mas a maioria mencionou a observação empírica em frases como "olhando o céu" e "quando há nuvens pretas" (Figura 2). Esta última também é uma forma válida de análise, além de não ter custo e não demandar competências cognitivas ou tecnológicas, podendo ser feita por uma criança ou por alguém que não tem pleno domínio da linguagem escrita. O problema relacionado à observação empírica do tempo é o curto intervalo de tempo entre a observação e a ocorrência do fenômeno meteorológico. $\mathrm{O}$ acesso à previsão do tempo fornecida pelos meios de comunicação de massa possibilitaria a antecipação de ações de proteção ou evacuação de locais de risco, em casos onde a precipitação excede o valor limite estipulado pela Defesa Civil. Entretanto, Oliveira e Nunes (2007) verificaram que "as informações que as pessoas recebem sobre as condições da atmosfera (noticiário, vivência pessoal/cultural) não são traduzíveis em elemento verdadeiramente relevante para elas, que desconhecem a marcha sazonal do clima e suas consequências (exemplo: precipitações mais fortes no verão)". Concatenando a discussão destas autoras com os resultados desta pesquisa, entendemos que é necessário um 
desenvolvimento conjunto de atividades educativas e preventivas, como estudos de percepção do ambiente, defesa e proteção civil e programas de educação ambiental, para que a sociedade possa efetivamente aproveitar a observação das situações cotidianas da atmosfera como forma de prevenção.

Para a pergunta "Você tem medo de chuva?" 182 estudantes do sexo feminino e 215 do masculino responderam NÃO enquanto 87 mulheres e 30 homens responderam SIM. 0 padrão de mais respostas negativas também se apresenta nas divisões por escola e por ano escolar (Figura 3). Chama a atenção a diferença entre as respostas entre o oitavo e o nono ano do ensino fundamental: no oitavo ano a maioria da classe respondeu que NÃO, enquanto no nono ano as respostas estiveram mais próximas de um equilíbrio $(53,8 \%$ NÃO e $46,2 \%$ SIM).

Esta pergunta foi elaborada com base no consenso existente na literatura científica sobre o papel da chuva na deflagração de escorregamentos, com trabalhos evidenciando esta correlação desde a década de 1960 (TATIZANA et. al., 1987; PICHLER, 1957; VARGAS; PICHLER, 1957; TALEBI et. al., 2007; COELHO NETTO et. al., 2011).

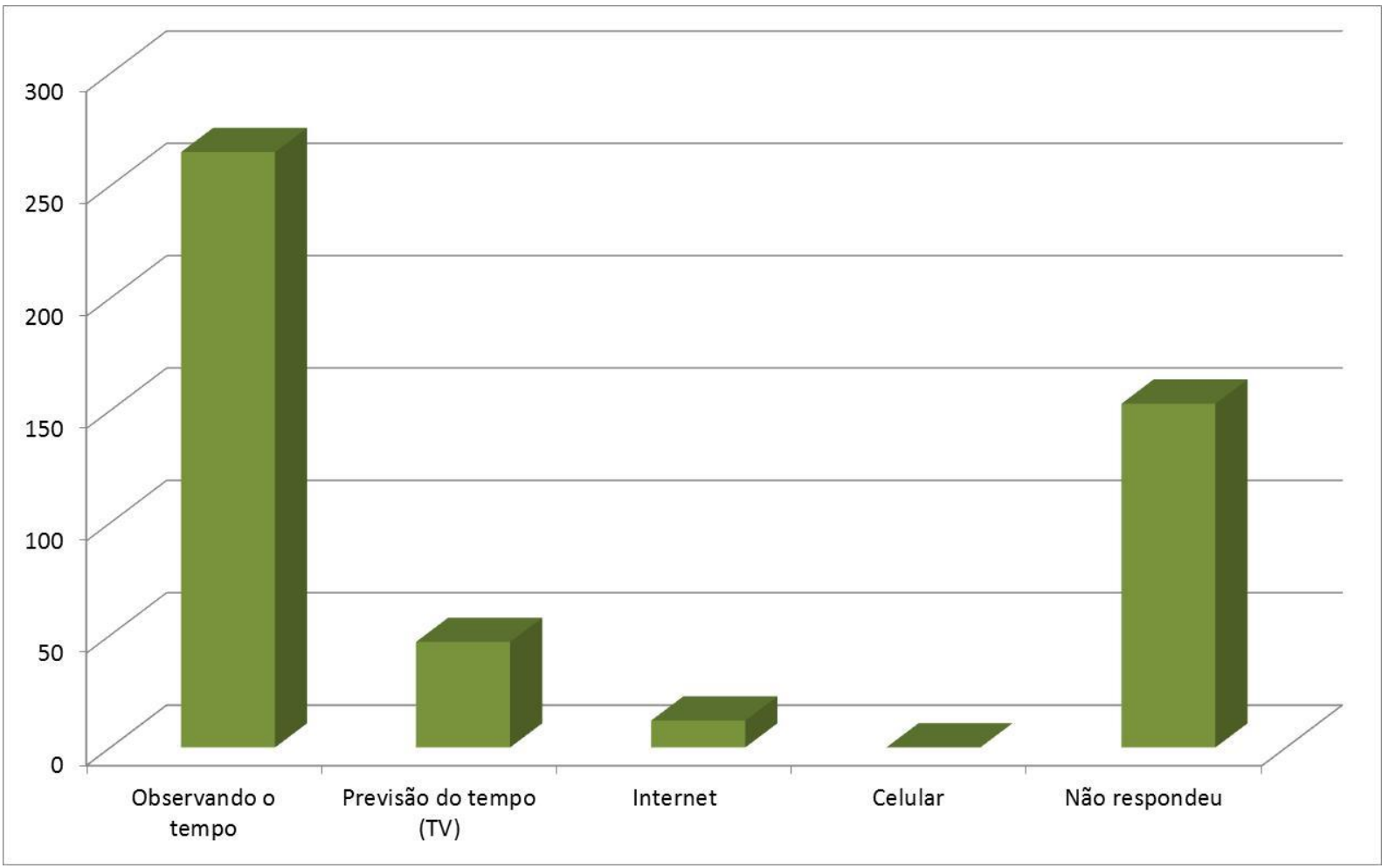

Figura 2: Formas de saber a possibilidade de chuva, de acordo com respostas dos estudantes para as perguntas "Você consegue saber quando vai chover? Como?"

Também contribuíram para a análise de percepção do risco as respostas para a pergunta "O que você acha que é pior: pancada de chuva ou chuva constante?". As respostas para chuva constante (total de 305: 154 - feminino e 151- masculino) e para pancada de chuva (total de 
209: 118 - feminino e 91 - masculino) mostram que aproximadamente $58 \%$ dos entrevistados acreditavam que chuva constante é pior que pancada de chuva. Entre os estudantes que moram em áreas de intervenção catalogadas pela Defesa Civil local, aproximadamente $55 \%$ responderam que chuva constante é pior (Tabela 2).

De acordo com Tatizana et. al. (1987), a água infiltrada no solo altera sua densidade, aumenta seu peso e diminui a coesão das partículas. O aumento de peso diminui a resistência ao cisalhamento e à compressão. Com o aumento da saturação do solo há uma diminuição da intensidade de precipitação suficiente para a deflagração de escorregamentos em uma razão geométrica (não linear) (TATIZANA et. al., 1987). A saturação depende de uma série de fatores: textura e estrutura do substrato, declividade da encosta, cobertura vegetal, estado prévio de saturação e tipologia das chuvas -chuvas de baixa intensidade e longa duração apresentam porcentagem de infiltração maior, enquanto chuvas de alta intensidade e curta duração favorecem o escoamento superficial (TATIZANA et. al., 1987).

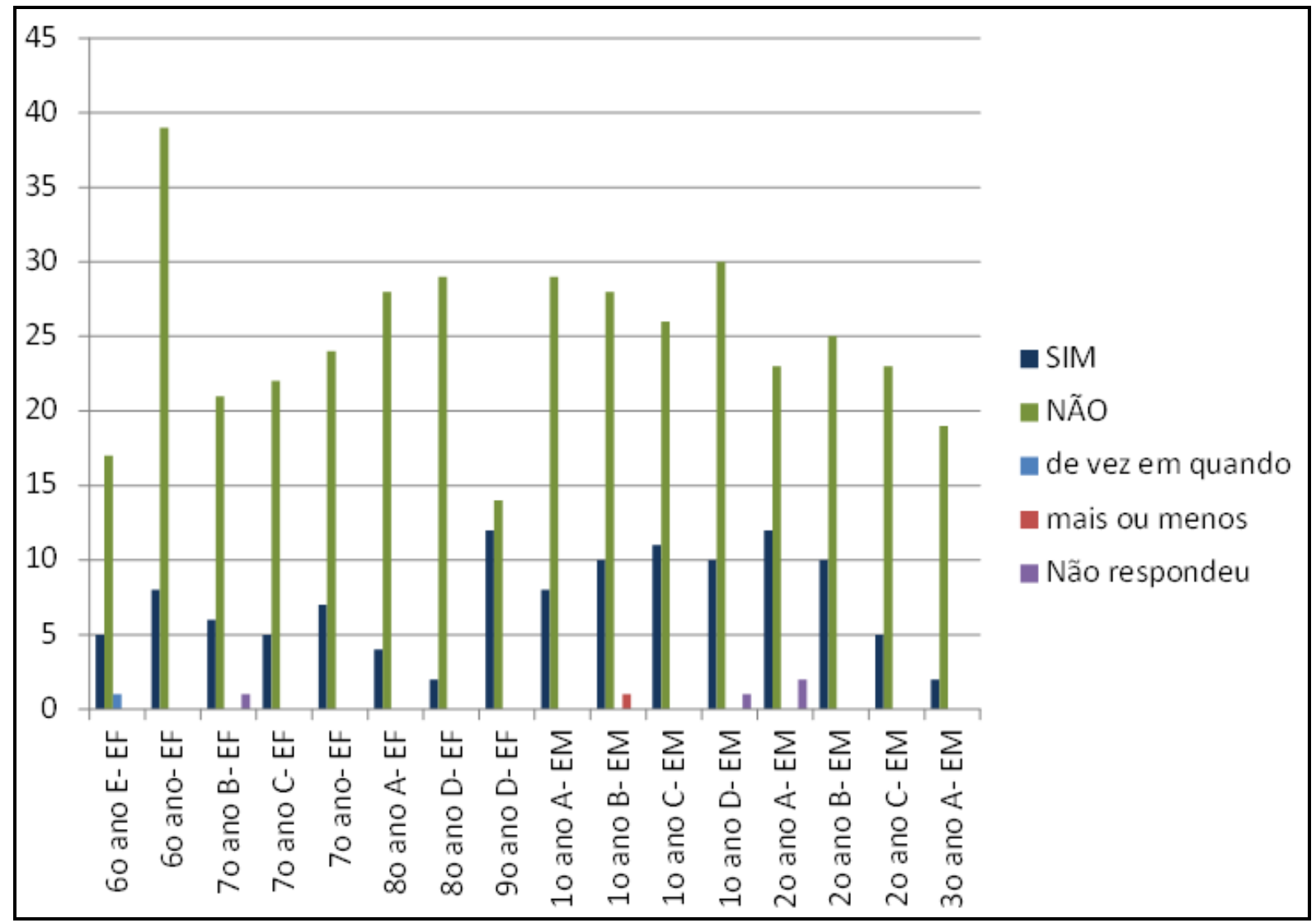




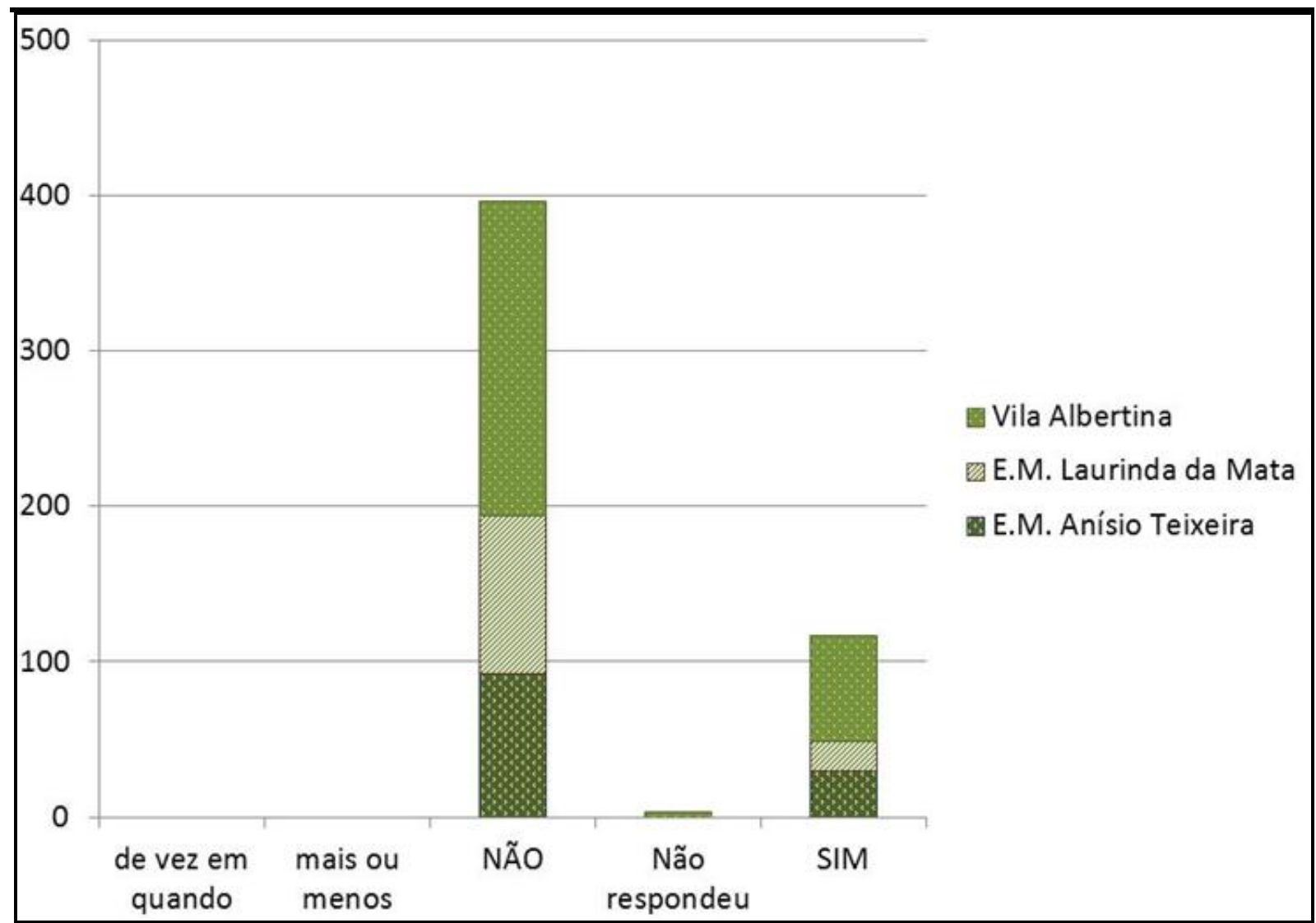

Figura 3: Respostas dos entrevistados para a pergunta "Você tem medo de chuva?" separados por ano escolar e por escola.

A importância das chuvas fortes ("pancadas de chuva") dependerá, portanto, do estado prévio de saturação do solo: fortes chuvas serão potencialmente mais perigosas em solos de alta saturação inicial. Consequentemente, as situações de maior risco de deslizamentos serão eventos de chuva contínua, com picos de intensidade no final do evento chuvoso (TATIZANA et. al., 1987).

As respostas obtidas na pesquisa demonstram que os estudantes que moram em áreas de risco têm uma noção de que a chuva pode lhes trazer problemas. Mesmo que esta noção não seja completamente elaborada ou que os conceitos envolvidos não sejam sólidos, é possível afirmar que há uma percepção dos estudantes sobre o risco associado à chuva.

As respostas dos moradores de áreas identificadas como locais de intervenção pela DC local revelam que eles acreditam na ocorrência de desastres no Brasil (Tabela 3). Entre este mesmo grupo, porém, estão em menor número aqueles que acreditam em desastres em Campos do Jordão e no bairro onde moram.Encontram-se em número ainda mais reduzido aqueles que admitem ter medo de um desastre e aqueles que reconhecem haver perigo no local onde moram (Tabela 3). Há duas ponderações sobre estas respostas, baseadas em conversas pessoais com os entrevistados: algumas pessoas realmente enxergam os desastres como algo distante de sua realidade: acreditam que pode acontecer no Brasil, mas 
não aconteceria ali onde vivem. Os dados apontam um fenômeno comum nos estudos de percepção que é, no caso dos riscos, a sensação de que o local de residência não é tão perigoso quanto outro bairro que também apresente riscos de movimentos de massa. $\mathrm{A}$ identidade com o lugar provoca uma sensação de que o "outro" esta em condições mais precárias, representando um perigo maior.

Tabela 2: Respostas para a pergunta "O que você acha que é pior: pancada de chuva ou chuva constante?" separadas pelo local de moradia dos entrevistados

\begin{tabular}{|c|c|c|c|c|}
\hline Bairro * & Chuva constante & Pancada de chuva & Não respondeu & Total Geral \\
\hline Acampamento dos Pumas & 1 & & & 1 \\
\hline Biquinha & & 1 & & 1 \\
\hline Brancas Nuvens & 16 & 19 & & 35 \\
\hline Britador & 13 & 7 & & 20 \\
\hline Fracalanza & & 5 & & 5 \\
\hline Gavião Gonzaga & & 1 & & 1 \\
\hline Jardim Guararema & & 1 & & 1 \\
\hline Matadouro & 2 & 1 & & 3 \\
\hline Morro Andorinhas & 3 & 3 & & 6 \\
\hline Vila Albertina & 56 & 32 & 2 & 90 \\
\hline Vila Paulista Popular & 7 & 3 & & 10 \\
\hline Vila Santo Antônio & 33 & 29 & 1 & 63 \\
\hline Vila Siomara & & 1 & & 1 \\
\hline Total & 131 & 103 & 3 & 237 \\
\hline
\end{tabular}

* Foram listados apenas os bairros considerados áreas de intervenção pela Defesa Civil local.

Outras pessoas acreditam na possibilidade do desastre onde moram, porém são conscientes de que suas respostas podem dar suporte a uma possível intervenção e retirada de suas famílias do local onde vivem. Ainda que muitos deles tenham respondido que suas famílias sairiam de suas casas em caso de desastre (Tabela 4), não desejam ser forçados a abandonar sua residência. A maioria dos entrevistados visualiza o quanto esta saída seria problemática e difícil. As respostas dos entrevistados só foram obtidas enfatizando-se o sigilo dos dados pessoais e, ainda assim, foi possível verificar a preocupação e o receio de intervenções da prefeitura e demais órgão públicos, para interdição de residência e retirada das famílias. 
Este entendimento do risco fica claro nas respostas para a pergunta "Você acredita que pode acontecer deslizamento de terra em Campos do Jordão? Onde?" (Figura 4). Há respostas genéricas, como "em casas construídas em morros" e "acontece em qualquer lugar, pois a maioria dos lugares tem morro e encosta" e há também respostas bastante específicas, onde são mencionados bairros e às vezes ruas. Entre os locais citados, a maioria coincide com áreas classificadas como locais de risco pela DC, mostrando que há um conhecimento dos locais de risco na cidade. Adicionalmente, 42 alunos identificaram o bairro onde moram como um local de risco.

É uma profunda ironia que frequentemente a cidade possa parecer um lugar assustador. Construída para corrigir a aparente confusão e o caos da natureza, a cidade em si mesma se transforma em um meio ambiente físico desorientador, no qual os prédios de apartamentos desabam sobre seus habitantes, ocorrem incêndios e o trânsito ameaça a vida e mutila as pessoas (TUAN, p. 233-234).

Ainda sobre as questões relacionadas ao medo e ao reconhecimento de perigo no local de moradia, o medo dos desastres teve menos importância com relação a outros perigos que os entrevistados enfrentam rotineiramente. Na avaliação das pessoas afetadas, há temas mais urgentes a serem resolvidos. Quando questionadas sobre segurança, fatores como venda/consumo de entorpecentes e assaltos/roubos/homicídios têm destaque nas respostas (por exemplo "matador e homem que usa drogas"). Este enfoque ocorre porque questões como insegurança e criminalidade são apontadas como os principais problemas da maior parte dos municípios brasileiros e também pela característica rotineira dos eventos citados, de ocorrência mais frequente que os desastres naturais. O medo de deslizamentos geralmente surge em momentos determinados: nos meses que registram os maiores índices de precipitação; em anos mais chuvosos, como consequência de fatores específicos como "El Niño" e quando ocorre algum deslizamento de terra que resulte em óbitos e apresente grande repercussão através dos meios de comunicação de massa.

Ao serem questionados sobre os sinais que apontam que a casa pode cair, os entrevistados responderam rachaduras (180), barulhos (44) e problemas estruturais (13). 60 alunos mencionaram outros sinais, como "casa envergando", "barranco próximo" e infiltração, mas a maioria não respondeu ou respondeu que não sabe. De acordo com os resultados, este deveria ser o tema prioritário a ser discutido em atividades educativas. 


\begin{tabular}{|c|c|c|c|c|c|}
\hline Bairro & $\begin{array}{c}\text { Acreditam em } \\
\text { desastres no } \\
\text { Brasil }\end{array}$ & $\begin{array}{c}\text { Acreditam em } \\
\text { desliza-mentos } \\
\text { em Campos do } \\
\text { Jordão }\end{array}$ & $\begin{array}{l}\text { Acreditam em } \\
\text { desliza-mentos no } \\
\text { bairro onde } \\
\text { moram }\end{array}$ & $\begin{array}{l}\text { Têm } \\
\text { medo }\end{array}$ & $\begin{array}{l}\text { Acham que } \\
\text { há perigo } \\
\text { onde } \\
\text { moram }\end{array}$ \\
\hline $\begin{array}{c}\text { Acampamento dos } \\
\text { Pumas }\end{array}$ & 1 & 1 & 1 & 1 & 1 \\
\hline Biquinha & 1 & 1 & 1 & 1 & \\
\hline Brancas Nuvens & 33 & 33 & 17 & 22 & 15 \\
\hline Britador & 22 & 20 & 19 & 13 & 16 \\
\hline Fracalanza & 5 & 5 & 5 & 2 & 4 \\
\hline Gavião Gonzaga & 1 & 1 & 1 & & \\
\hline Jardim Guararema & 1 & 1 & 1 & & \\
\hline Matadouro & 3 & 3 & 1 & 1 & 1 \\
\hline Morro Andorinhas & 6 & 4 & 4 & 3 & 3 \\
\hline Vila Albertina & 86 & 83 & 48 & 46 & 25 \\
\hline Vila Paulista Popular & 10 & 10 & 7 & 6 & 6 \\
\hline Vila Santo Antônio & 62 & 57 & 52 & 39 & 20 \\
\hline Vila Siomara & & & 1 & & 1 \\
\hline Total Geral & 231 & 219 & 158 & 134 & 92 \\
\hline
\end{tabular}

Alguns entrevistados apresentam ainda uma mistura de conceitos e palavras-chave que ouvem no seu dia a dia. Um aluno, na pergunta "o que causa o deslizamento de terra?" responde "Lixo na rua e água suja". Esta criança teve acesso à discussão de temas como poluição e ambiente e identifica o lixo na rua e a água suja como problemas, mas não sabe estabelecer uma relação de causa e efeito entre os temas que cita. Há também um forte apelo de imagens que a criança ou adolescente acompanha na mídia. Um exemplo é a resposta "muitas casas juntas" para a mesma pergunta sobre as causas do deslizamento de terra. Quando são apresentados episódios de deslizamento de terra na mídia, sempre há imagens de "muitas casas juntas", sendo esta a informação resgatada na memória do estudante. Neste caso, a presença de muitas moradias em uma área pequena pode aumentar o número de vítimas caso ocorra um deslizamento de terra, porém a construção de uma única moradia com corte irregular do talude pode provocar o deslizamento de terra se não houver medidas adequadas de contenção. 


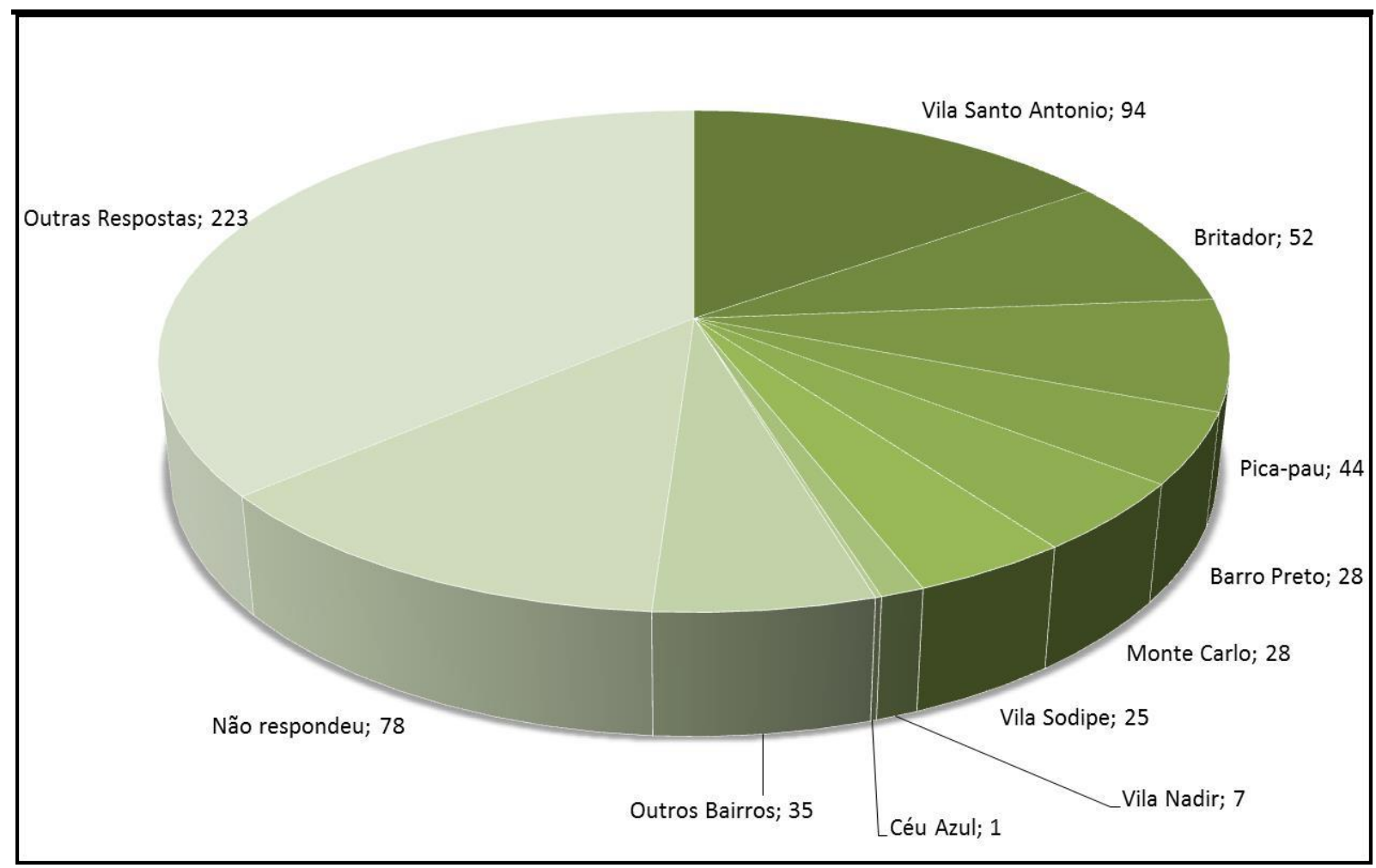

Figura 4: Respostas para a pergunta "Você acredita que pode acontecer deslizamento de terra em Campos do Jordão? Onde?" Alguns alunos indicaram mais de um bairro. Nota: Barro Preto e Vila Santo Antônio correspondem à mesma localização, porém optamos por manter os nomes originais mencionados nas respostas.

Esta confusão por parte dos estudantes corrobora o questionamento de Veyret (2007) sobre o processo da comunicação do risco:

Nessa abordagem do risco, coloca-se a questão da comunicação e da informação que acompanham medidas negociadas. Como informar? O que deve ser privilegiado, precisão técnica e científica ou a compreensão pelo grande público? Como apresentar as dúvidas e as incertezas, sabendo que certas campanhas de informação têm consequências negativas e que conduzem ao oposto do que era desejado? (p. 16)

É importante que as informações divulgadas, principalmente aquelas veiculadas em televisão, sejam cuidadosamente revisadas para que atuem como fonte de esclarecimento da população, aumentando sua capacidade de prevenção.

\section{Receptividade dos entrevistados para intervenções institucionais e ações educativas}

Entre os alunos que moram em locais de risco ou áreas de intervenção, muitos alunos conhecem a Defesa Civil(DC) $(55,41 \%)$. Agentes deste órgão municipal já visitaram o bairro de $74,36 \%$ dos entrevistados, apontando para uma atuação intensa destes profissionais, porém poucas pessoas $(16,32 \%)$ saberiam entrar em contato com eles, pois a maioria 
desconhece o número de telefone emergencial e gratuito da DC (Tabela 4). Isto demonstra que em uma situação de emergência provavelmente a DC não seria acionada pelos moradores do local em risco em tempo hábil para atividades de mitigação e resposta.

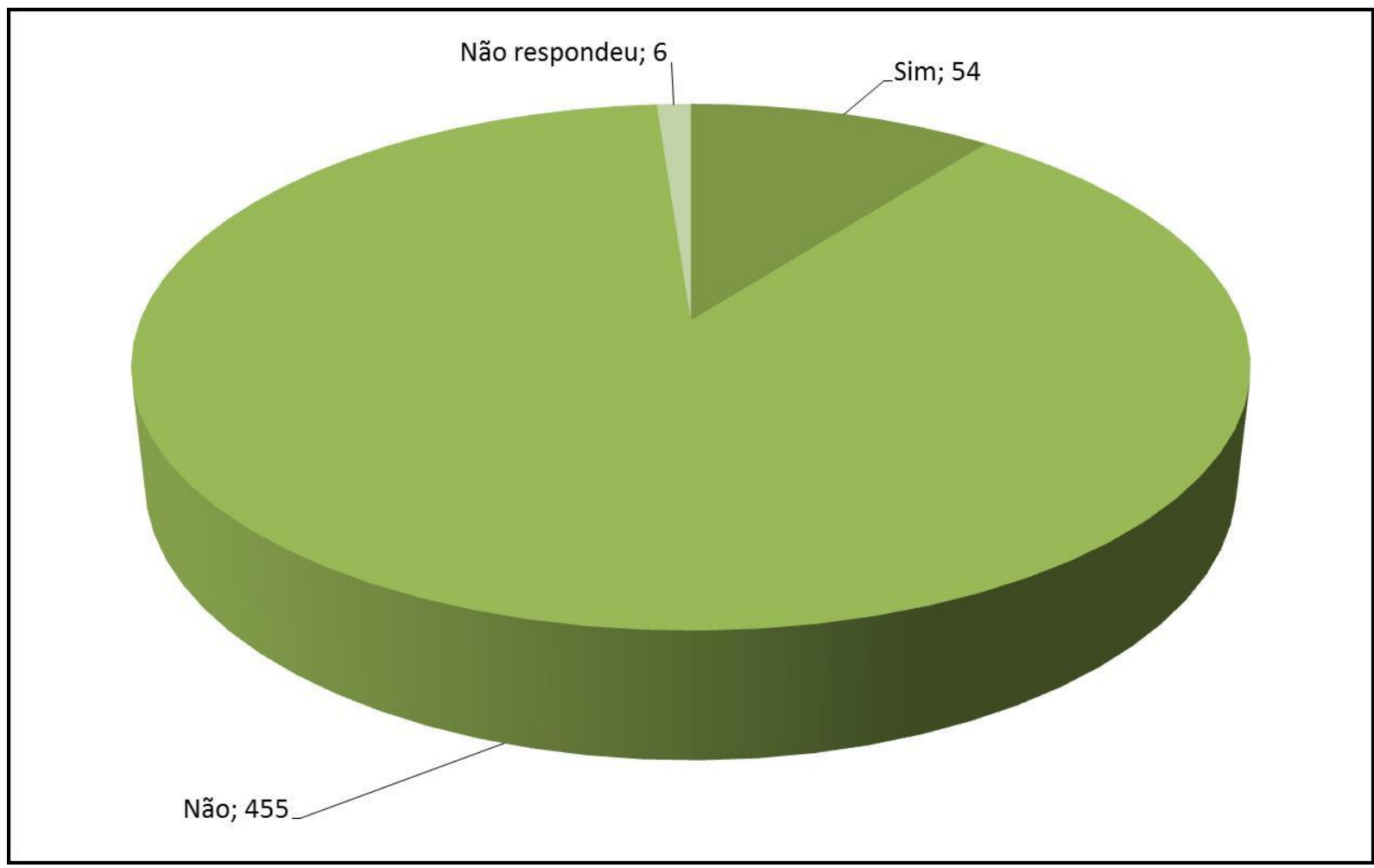

Figura 5: Respostas para a pergunta "Você já teve que sair de casa por causa de um deslizamento?"

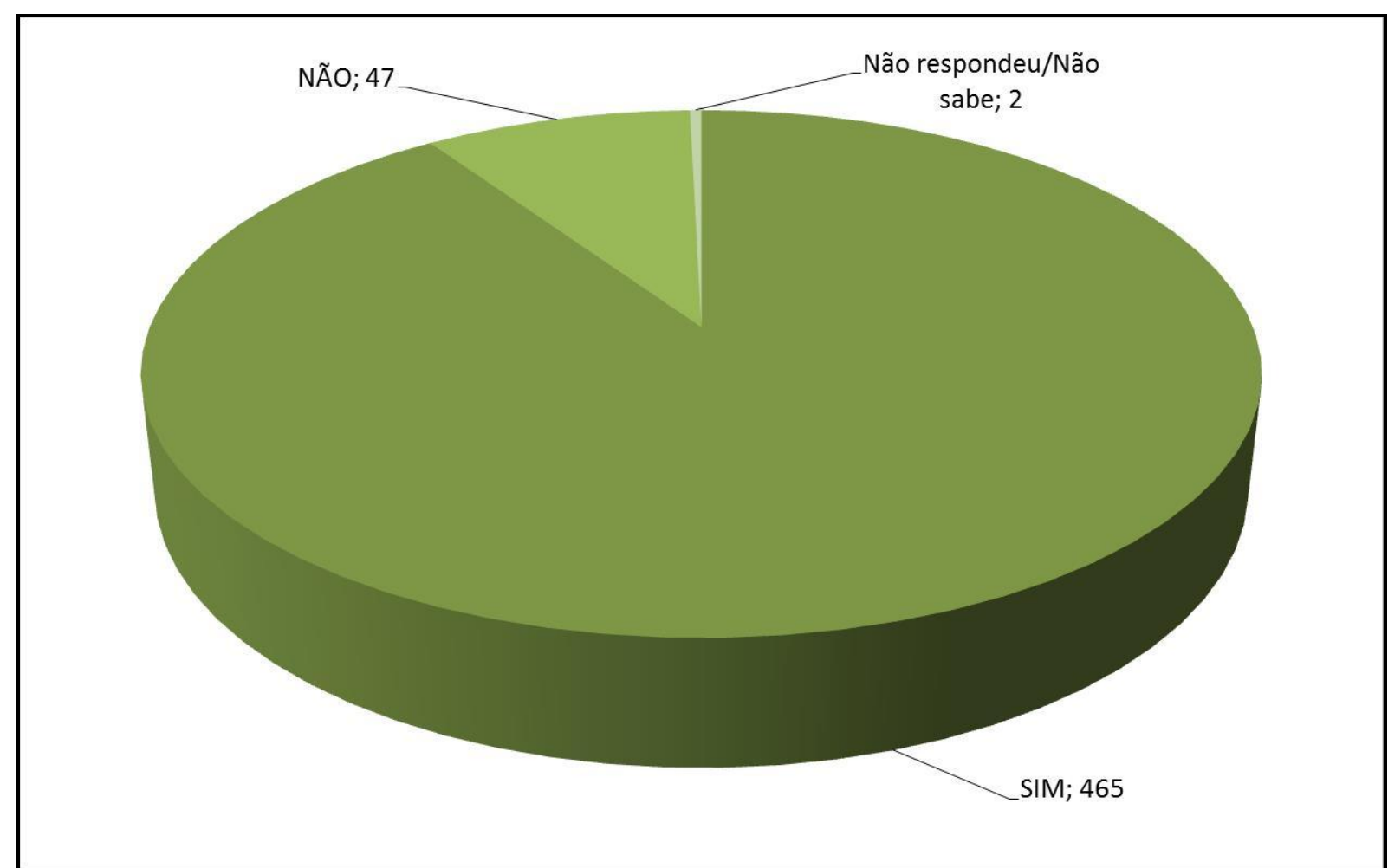

Figura 6: Respostas para a pergunta "Você acha que as pessoas que moram com você aceitariam sair de casa numa situação de risco de deslizamento?( ) sim ( ) não." 
Entre os alunos entrevistados, $88,35 \%$ nunca tiveram que sair de casa por causa de um deslizamento (Figura 5). Se fosse necessário evacuar a residência devido a riscos de deslizamento, $90 \%$ dos entrevistados acreditam que as pessoas que moram em sua residência aceitariam sair de casa(Figura 6) e 69\% disseram contar com casas de familiares para se abrigar(Figura 7). Estes números apontam para um cenário de planejamento, ainda que empírico para ações pré e/ou pós-impacto. Porém, ressalta-se que $10 \%$ dos alunos entrevistados acreditam que os pais ou responsáveis não sairiam de suas casas, nem mesmo com a indicação de risco alto de deslizamento por parte de autoridades de DC. Uma porcentagem elevada de famílias que, possivelmente, optariam por aceitar o risco.

Ressalta-se que foi registrada a opinião da criança ou do jovem em relação a medidas e ações a serem tomadas em situação de risco de desastre. Embora sejam limitados pelas ações adotadas pelos pais ou responsáveis, é fundamental buscar a opinião e a percepção dos alunos em relação ao assunto. Neste sentido, a educação voltada para a redução de desastres, focando os ensinos médios e fundamental pode representar a conscientização de um cidadão que pode reproduzir os conceitos em casa, com o núcleo familiar atual, ou no futuro.

71,55\% dos alunos entrevistados afirmaram que não aprenderam sobre prevenção de desastres na escola, 96,23\% acham importante aprender sobre este assunto e $97,49 \%$ gostariam de receber a DC para discutir a prevenção de desastres. Estes resultados mostram uma ótima receptividade por parte dos estudantes para discutir este tema com a DC ou com outros profissionais. A prevenção de desastres como tema transversal, portanto, contaria com o interesse dos estudantes e poderia incluir palestras ou encontros diversos com os profissionais da DC. 


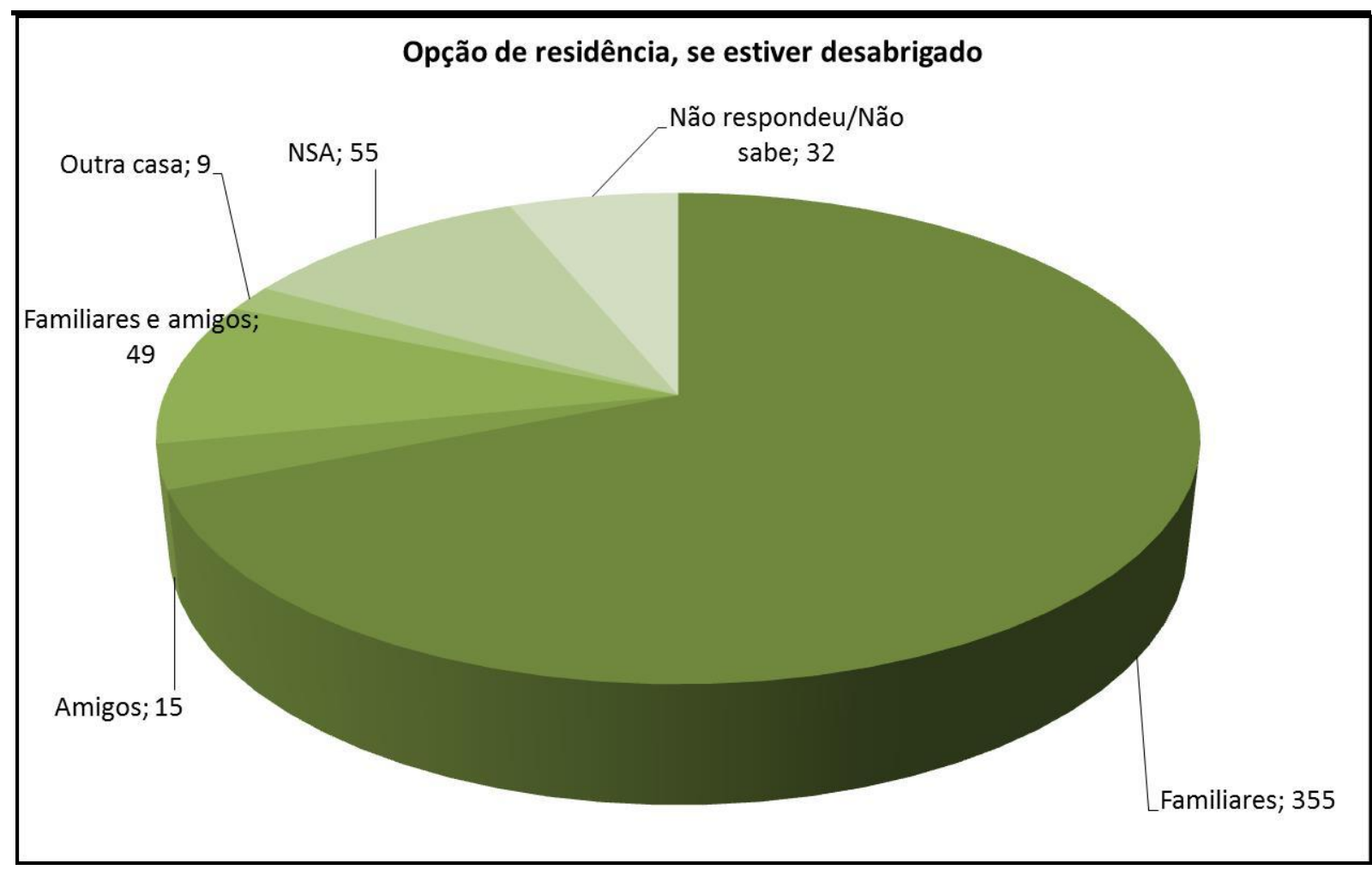

Figura 7: Respostas para a pergunta "Se for preciso sair de casa por causa da chuva, você tem outra casa para ir (parentes, avós, amigos, tios)?( ) sim ( ) não - Quem?" NSA: Não se aplica - refere-se às respostas negativas para a primeira pergunta.

Acreditamos que as atividades paradidáticas com os alunos de primeiro e segundo grau são um fator-chave na busca pela resiliência e no aumento da capacidade de resposta.

As crianças devem fazer parte das soluções dos problemas, pois a sua preparação pode garantir, numa outra situação de risco, que elas consigam se proteger e alertar a própria família ou irmãos menores para que os danos humanos sejam minimizados ou evitados. É a partir das informações que thes são transmitidas pelo convívio social, que elas reagem e atuam diante das mais diversas situações(PAVAN, 2009, p. 97).

As crianças, portanto, podem ser o fator motivador para que adultos também assumam seu importante papel nas atividades de prevenção de desastres.

Um fato básico da condição humana é a vulnerabilidade da criança, o longo período de dependência dos pais; outro fato igualmente básico é a necessidade dos adultos de cooperar para poder sobreviver e sustentar um mundo. Os muitos desafios e ameaças da natureza podem ser superados somente quando os seres humanos se unem e exercem seu poder (TUAN, 2005, p. 330). 


\begin{tabular}{|c|c|c|c|c|c|c|c|c|c|c|c|c|c|c|}
\hline \multirow[b]{2}{*}{ Bairro } & \multicolumn{2}{|c|}{$\begin{array}{c}\text { Conhece a } \\
\text { DC? }\end{array}$} & \multicolumn{2}{|c|}{$\begin{array}{l}\text { Sabe o } \\
\text { telefone } \\
\text { da DC? }\end{array}$} & \multirow{2}{*}{$\begin{array}{c}\text { DC foi } \\
\text { ao } \\
\text { bairro? } \\
\text { NÃO }\end{array}$} & \multicolumn{2}{|c|}{$\begin{array}{c}\text { Sairiam } \\
\text { de } \\
\text { casa? }\end{array}$} & \multicolumn{2}{|c|}{$\begin{array}{l}\text { Aprendeu } \\
\text { sobre } \\
\text { prevenção? }\end{array}$} & \multicolumn{3}{|c|}{$\begin{array}{c}\text { Acha } \\
\text { importante? }\end{array}$} & \multicolumn{2}{|c|}{$\begin{array}{l}\text { Gostaria de } \\
\text { aprender? }\end{array}$} \\
\hline & NÃO & SIM & NÃO & SIM & & SIM & NÃO & SIM & NÃO & SIM & NÃO & SIM & NÃO & SIM \\
\hline $\begin{array}{l}\text { Acampa- } \\
\text { mento dos } \\
\text { Pumas }\end{array}$ & 1 & & 1 & & & 1 & & 1 & 1 & & & 1 & & 1 \\
\hline Biquinha & 1 & & 1 & & & 1 & & 1 & 1 & & & 1 & & 1 \\
\hline $\begin{array}{l}\text { Brancas } \\
\text { Nuvens }\end{array}$ & 16 & 16 & 30 & 5 & 12 & 23 & 3 & 32 & 29 & 6 & 1 & 34 & & 35 \\
\hline Britador & 12 & 9 & 16 & 6 & 4 & 18 & 4 & 18 & 18 & 4 & & 22 & & 22 \\
\hline Fracalanza & 1 & 4 & 5 & & 1 & 4 & 1 & 4 & 5 & & & 5 & 1 & 4 \\
\hline $\begin{array}{l}\text { Gavião } \\
\text { Gonzaga }\end{array}$ & & 1 & & 1 & & 1 & & 1 & & 1 & & 1 & & 1 \\
\hline $\begin{array}{l}\text { Jardim } \\
\text { Guararema }\end{array}$ & & 1 & 1 & & & 1 & & 1 & & 1 & & 1 & 1 & \\
\hline Matadouro & & 3 & 2 & 1 & & 3 & & 3 & 3 & & & 3 & & 3 \\
\hline $\begin{array}{c}\text { Morro } \\
\text { Andorinhas }\end{array}$ & 2 & 4 & 6 & & 4 & 1 & & 6 & 4 & 2 & 1 & 5 & & 6 \\
\hline $\begin{array}{c}\text { Vila } \\
\text { Albertina }\end{array}$ & 44 & 43 & 79 & 11 & 28 & 60 & 8 & 80 & 59 & 31 & 3 & 87 & 3 & 87 \\
\hline $\begin{array}{l}\text { Vila Paulista } \\
\text { Popular }\end{array}$ & 3 & 7 & 10 & & 5 & 5 & & 10 & 7 & 3 & 1 & 9 & & 10 \\
\hline $\begin{array}{l}\text { Vila Santo } \\
\text { Antônio }\end{array}$ & 23 & 40 & 49 & 14 & 6 & 55 & 9 & 54 & 44 & 19 & 3 & 60 & 1 & 62 \\
\hline $\begin{array}{c}\text { Vila } \\
\text { Siomara }\end{array}$ & & & & 1 & & 1 & & 1 & & 1 & & 1 & & 1 \\
\hline Total & 103 & 128 & 200 & 39 & 60 & 174 & 25 & 212 & 171 & 68 & 9 & 230 & 6 & 233 \\
\hline
\end{tabular}

\section{CONSIDERAÇÕES FINAIS}

Apesar da presença de várias áreas de risco em Campos do Jordão, a maioria dos entrevistados não reconhece este risco como parte de sua realidade. Recomendamos que este seja o ponto de partida de atividades educacionais sobre desastres.

Foi possível constatar, com base nas respostas, que as imagens às quais os alunos têm acesso contribuem para formar seus conceitos sobre diversos temas, incluindo os desastres. 
Sugerimos que futuros trabalhos explorem com mais detalhes os conceitos e informações visuais das crianças e adolescentes, pois todos os trabalhos de educação e conscientização devem ter como base e como ponto de partida os conceitos prévios (mesmo que equivocados) do público alvo sobre o tema a ser tratado.

A maioria dos entrevistados não soube responder sobre os sinais que apontam que a casa pode cair, por isso sugerimos que atividades escolares sobre desastres contemplem e destaquem este sub-tema importante e ainda pouco discutido.

Entre os moradores de áreas de risco mencionados nos questionários há crianças, idosos e pessoas com necessidades especiais. É importante que a DC, juntamente com as comunidades envolvidas, elabore um planejamento especial de ações de evacuação para os diferentes grupos vulneráveis na iminência de um desastre e também medidas diferenciadas de atendimento pós-impacto.

Os entrevistados mostraram-se receptivos às ações da DC e a discussões gerais sobre o tema desastres. Recomendamos uma parceria entre as escolas e a DC local para atividades de educação e planejamento.

A maioria dos alunos entrevistados (455) é natural do município e representa um número significativo da população total de Campos do Jordão. Considerando-se as áreas de risco do município, o número de pessoas vulneráveis aos deslizamentos e o histórico de ocorrência dos mesmos, ações educativas e informativas relativas à prevenção e mitigação de desastres seriam fundamentais para a redução da vulnerabilidade.

\section{AGRADECIMENTOS}

À Defesa Civil de Campos do Jordão, pelo apoio e parceria.Aos Diretores e coordenadores das escolas Anísio Teixeira, Laurinda da Mata e "Vila Albertina". Ao Paulo J. V. Leal, por sua valiosa contribuição.

\section{REFERÊNCIAS BIBLIOGRÁFICAS}

AUGUSTO FILHO, O. 1994. Carta de riscos de escorregamentos: uma proposta metodológica e sua aplicação no município de Ilha Bela, SP. 1994. 168f. Dissertação (Mestrado) - Escola Politécnica, Universidade de São Paulo, São Paulo. 
BARREIROS, J. (2002). A Criança e a Percepção do Risco. Livro de resumos do Congresso

"Crescer em Segurança - 10 anos depois" promovido pela Associação para a Promoção da Segurança Infantil (APSI) (s/p).

BECK,U.; GIDDENS, A.; LASH, S. Modernização reflexiva. Política, tradição e estética na ordem social moderna. Tradução de Magda Lopes. Revisão Técnica de Cibele SalibaRizek. São Paulo: Editora da Universidade Estadual Paulista, 1997.

BRASIL. Secretaria de Educação Fundamental. Parâmetros curriculares nacionais: meio ambiente e saúde. / Secretaria de Educação Fundamental. Brasília-DF, 1997, 128p. Disponível em < http://portal.mec.gov.br/seb/arquivos/pdf/livro091.pdf>. Acesso em: 13 ago. 2013

BRASIL. Presidência da República Casa Civil- Subchefia para Assuntos Jurídicos.Leino 12.608, de 10 de abril de 2012. Institui a Política Nacional de Proteção e Defesa Civil - PNPDEC.... Disponível em:<http://www.planalto.gov.br/ccivil_03/_Ato20112014/2012/Lei/L12608.htm.>. Acesso em: 8 ago. 2013

CERRI, L.E.S. Riscos geológicos associados a escorregamentos: uma proposta para a prevenção de acidentes. 1993. 197f. Tese (Doutorado) - Instituto de Geociências e Ciências Exatas da Universidade Estadual Paulista, IGCE/UNESP, Rio Claro, São Paulo.

COELHO NETTO, A.L.; et. al. January 2011: the extreme landslide disaster in Brazil. In: PROCEEDINGS OF THE SECOND WORLD LANDSLIDE FORUM.3-7 October 2011, Rome. p. 303304.

$\begin{array}{llll}\text { DIRETRIZES: } & \text { Por dentro dos } & \text { PCN. }\end{array}$ em:<http://educarparacrescer.abril.com.br/indicadores/materias_295305.shtml\#>. Acesso em: 13 ago. 2012

FARIA, E.O. Bases para um programa de educação para o trânsito a partir do estudo de percepção de crianças e adolescentes. 2002. 524f.Tese (Doutorado) - COPPE/UFRJ, Rio de Janeiro.

FIBGE/IBGE. Disponível em < http://www.ibge.gov.br/home/>. Acesso em: 06 set. 2013

FUNDAÇÃO SEADE. Pesquisa de ..... Paulo, 2006 
IPT. Instituto de Pesquisa Tecnológica. 2000. Relatório Técnico sobre Campos do Jordão-SP. (Relatório Final no 64.399/Divisão de Geologia).

IPT. Instituto de Pesquisa Tecnológica. 2002. Risco: definição e classificação. Fonte: www.ipt.br. Acessado em 20/03/2005.não aparece no texto...

IPT. Instituto de Pesquisa Tecnológica. 2003. Mapa de declividade dos bairros: Britador, Vila Santo Antônio e Andorinha em Campos do Jordão-SP.

LIMA, J.N.A. Defesa civil na escola./João Nilo de Abreu Lima. - Brasília: Secretaria Nacional de Defesa $\quad$ Civil, 2006.233 p. Disponível em < http://www.integracao.gov.br/c/document_library/get_file?uuid=35997b78-280a-4c0baf3d-e0b499bdff17\&groupld=10157>. Acesso em: 01 out. 2013

MINAYO, M.C. de S. O desafio do conhecimento: pesquisa qualitativa emsaúde. 8 ed. São Paulo: Hucitec, 2004.

MODENESI-GAUTTIERI, M.C.; HIRUMA, S.T. A expansão urbana no planalto de Campos do Jordão. diagnóstico geomorfológico para fins de planejamento. Revista do Instituto Geológico, São Paulo, 25(1/2), 1-28, 2004.

OLIVEIRA, F. L.; NUNES, L. H.A percepção climática no município de Campinas, SP: confronto entre o morador urbano e o rural. Geosul, Florianópolis, v. 22, n. 43, p 77-102, jan./jun. 2007.

PAVAN, B.J.C. O olhar da criança sobre o desastre: uma análise baseada em desenhos. In: VALENCIO, N.; SIENA, M.; MARCHEZINI, V.; GONÇALVES, J.C. Sociologia dos desastres: construção, interfaces e perspectivas no Brasil. São Carlos: Rima Editora, 2009. p. 96-106.

PICHLER, E. 1957. Aspectos geológicos dos escorregamentos de Santos. Boletim da Sociedade Brasileira de Geologia, São Paulo, 6(2): 69-77.

SÃO PAULO (Estado). Governo do Estado de São Paulo. Secretaria de Estado da Educação. Planejamento escolar 2012: temas transversais. Disponível em:< http://www.educacao.sp.gov.br/docs/CGEB_PlanejEscolar2012_DEGEB_TemasTransversais \%20copy.pdf>.Acessoem: 14 jun. 2012. 
VARGAS, M.; PICHLER, E. 1957.Residual soil and rocks slides in Santos (Brazil).International Conference on Soil Mechanics and Foundation Engineering, 4, London, 1957. Proceedings... London, International Society for Soil Mechanics and Foundation Engineering, v. 2, tema 6, trabalho 6/27. p. 394-398.

ROSA-FILHO, A.; CORTEZ, A.T.C. A problemática sócioambiental da ocupação urbana em áreas de risco de deslizamento da "Suíça Brasileira". Revista Brasileira de Geografia Física, 03 (2010) $33-40$.

Disponível

em

<http://www.revista.ufpe.br/rbgfe/index.php/revista/article/viewFile/76/76>. Acessoem: 10 set. 2013

SELBY, M.J. Hillslope materials and processes. 2ed. Oxford: Oxford Univ. Press, 1993. 451p.

TALEBI, A.; UIJLENHOET, R.;TROCH, P.A. Soil moisture storage and hillslope stability. Nat. Hazards Earth Syst. Sci., 7, 523-534, 2007.

TATIZANA, C.; et. al. Análise de correlação entre chuvas e escorregamentos - Serra do Mar Município de Cubatão. In: CONGRESSO BRASILEIRO DE GEOLOGIA DE ENGENHARIA, 5, São Paulo, SP.Anais...São Paulo: ABGE, 1987, v.2, p. 225-236.

TOMINAGA, L.K. 2007. Avaliação de metodologias de análise de risco a escorregamentos: aplicação de um ensaio em Ubatuba, SP. 2007. 220f. Tese (Doutorado) - Departamento de Geografia da Faculdade de Filosofia, Letras e Ciências Humanas. Universidade de São Paulo, São Paulo.

TOMINAGA, L.K.; SANTORO, J.;AMARAL, R. do (Organizadores). Desastres naturais: conhecer para prevenir. São Paulo: Instituto Geológico, 2009. 196 p. Disponível em: < www.igeologico.sp.gov.br/.../DesastresNaturais.pdf>. Acesso em: 12 set. 2013

TUAN, Y.Paisagens do medo. Tradução Lívia de Oliveira. São Paulo: Editora UNESP, 2005.

VALENCIO, N.; et. al. Chuvas no Brasil: representações e práticas sociais. Politica \& Sociedade, Florianópolis, PPGSocPol/ UFSC, v. 4, n. 07, p. 163-183, 2005.

VALENCIO, N. A gestão de desastres como prática institucional de reiteração da violência contra grupos vulneráveis: o caso dos abrigos temporários. In: XIII Congresso Brasileiro de Sociologia, 2007, Recife. Acesso eletrônico. UFPE: Recife, 2007. p. 1-14. 
VEYRET, Y. (organizadora). Dilson F. da C. (tradutor). Os riscos: o homem como agressor e vítima do meio ambiente. 1 ed., 1ạ reimpressão. São Paulo: Contexto, 2007.

PIAGET, J. O raciocínio na criança. Ed. Record. Rio de janeiro. 1967.

Artigo recebido em 13/01/2014.

Artigo aceito em 21/01/2014. 